\title{
Brote de gastroenteritis en fiesta familiar
}

\author{
Gastroenteritis outbreak in a family party
}

A

Emergencia de una afamada clínica de la capital concurrieron sucesivamente varios adultos jóvenes, elegantemente vestidos y bien parecidos pero de mal semblante, hasta enterar la cifra de 16 , todos aquejados por vómitos y diarrea profusa. En sus deplorables condiciones fueron internados para hidratarlos, lamentándose cada cual de haber asistido a un banquete familiar la noche anterior en el domicilio de una empingorotada tía abuela.

Mientras eran atendidos e hidratados, los médicos iniciaron el interrogatorio de rigor en busca del alimento responsable de tan desagradable brote epidémico. Como hipótesis obvia surgió "la mayonesa". Efectivamente, había sido hecha en casa de la tía abuela a quien se le acercaron en forma inquisidora dos médicos de turno; ella, al verse acosada adoptó un gesto de complicidad con los doctores y les secreteó al oído... ¡no se le ocurra a nadie comentar lo de la mayonesa porque usamos huevos de mi fundo y nosotros tenemos una empresa avícola de donde provinieron los huevos!

Transcurrieron unos minutos hasta que los médicos hubieron encuestado a los 16 afectados concluyendo que no todos habían ingerido tal mayonesa. El alimento tendría que ser otro.

Al cabo de la "encuesta alimentaria" uno de los doctores regresó donde la distinguida tía abuela con la buena nueva: ¡no fue la mayonesa, Sra. Encarnación! ¡Fueron unas ostras consumidas por todos los pacientes! La reacción de ella fue: ... abrir tamaños ojos, hacer un gesto de silencio al médico y soplarle esta vez: ... “¡Mi’jito, qué barbaridad!... ipero si también somos productores de ostras!" 